\title{
Erratum to: The role of flatfishes in the organization and structure of the eastern Bering Sea ecosystem
}

\author{
Sung Il Lee $\cdot$ Kerim Y. Aydin $\cdot$ Paul D. Spencer • \\ Thomas K. Wilderbuer $\cdot$ Chang Ik Zhang
}

Published online: 20 April 2010

(C) The Japanese Society of Fisheries Science 2010

\section{Erratum to: Fish Sci}

DOI 10.1007/s12562-009-0201-2

In the 5th paragraph of the "Model structure" subheading of the "Data and methods", lines 6-8 of the text should read: "...the immigration of $i, Y_{i}$ is the yield of $i$ (i.e., its catch in weight, with $Y_{i}=F_{i} B_{i}$, where $F$ is the fishing mortality rate), $B_{j}$ is the biomass of the consumers or predators,...".

On the 2nd and 4th pages of Table 2, "35 Myc. \& Bathy." in the column headed "Prey/predator" should be
"35 Myc. \& bathy." In Fig. 4, "Myc. \& Bathy." on the $y$ axis should also be "Myc. \& bathy."

In addition, under the "Ecosim analyses" subheading of the "Results", in the 1st paragraph lines 9-11 should read: "...Arrowtooth flounder had biomass 3.7 times higher in 2005 , and Greenland turbot showed the fastest rate of decrease”. In the 2nd paragraph lines 17-18 should read: "...It was only the rate of increase or decrease in the biomass of flatfishes...".

The online version of the original article can be found under doi:10.1007/s12562-009-0201-2.

S. I. Lee $(\square)$

East Sea Fisheries Research Institute, National Fisheries, Research and Development Institute, Gangnung 210-861, Korea e-mail: silee@nfrdi.go.kr

K. Y. Aydin · P. D. Spencer - T. K. Wilderbuer Alaska Fisheries Science Center, National Marine Fisheries Service, 7600 Sand Point Way NE, Bldg. 4,

Seattle, WA 98115, USA

C. I. Zhang Pukyong National University, Daeyeon 3-dong, Nam-gu, Busan 608-737, Korea 